\title{
COMPOSTOS SECUNDÁRIOS EM CACHAÇAS PRODUZIDAS NO ESTADO DE MINAS GERAIS
}

\author{
NORMA ELIANE PEREIRA ${ }^{1}$ \\ MARIA DAS GRAÇAS CARDOSO ${ }^{2}$ \\ SEBASTIÃO MÁRCIO DE AZEVEDO ${ }^{3}$ \\ AUGUSTO RAMALHO DE MORAIS ${ }^{4}$ \\ WELINGTON FERNANDES ${ }^{5}$ \\ PRISCILA MENDES AGUIAR ${ }^{5}$
}

\begin{abstract}
RESUMO - Os componentes da cachaça classificados como secundários constituem um grupo de produtos minoritários oriundos do processo de fermentação. Esses, especialmente os ésteres e aldeídos, são responsáveis pelo aroma e sabor dos destilados em geral, porém, quando se encontram acima dos limites estabelecidos pelo Ministério da Agricultura, Pecuária e Abastecimento (MAPA), podem comprometer a qualidade da cachaça e ser prejudicial à saúde. Com o intuito de avaliar os compostos secundários de aguardentes provenientes de várias localidades do Estado de Minas Gerais,
\end{abstract}

foram coletadas 45 amostras aleatoriamente e conduzidas ao Laboratório de Análise Físico-Química de Aguardente (LAFQA) da UFLA, no período de agosto de 2000 a julho de 2001. Pelos resultados, verificou-se que há diferenças altamente significativas entre as amostras analisadas para acidez volátil, ésteres, aldeídos e álcoois superiores. De todas as amostras analisadas, sete apresentaram excesso de álcoois superiores, duas de aldeídos e três de acidez volátil; portanto, $24,44 \%$ das aguardentes encontravam-se fora dos padrões de qualidade estabelecidos pelo MAPA (1997).

TERMOS PARA INDEXAÇÃO: Cachaça, aguardente de cana-de-açúcar, compostos secundários.

\section{SECUNDARY COMPOUNDS IN BRAZILIAN SUGAR-CANE SPIRITS ("CACHAÇA") MANUFACTURED IN MINAS GERAIS STATE}

\begin{abstract}
The Brazilian sugar-cane spirit chemical compounds classified like secondary compounds are one group of Brazilian sugar-cane spirit minor compounds formed during the fermentation process. That compounds are important for the taste and flavor of spirits in general, mainly esters and aldehydes. However, that compounds are above the standard quality established by Agriculture Ministry (MAPA), they can affect the Brazilian sugar-cane spirit quality and be harmful to the health. Aiming to evaluate the sugar-cane spirit secondary compounds from diverse sites at Minas Gerais State, 45 samples
\end{abstract}

were randomized sampled and taken to the Brazilian Sugar-Cane Spirit Analysis Laboratory of UFLA during the period of August of 2000 to July of 2001. The results showed that there were high and significant statistical difference between the samples analyzed regarding higher alcohol, esters, aldehydes and volatile organic acids. Among 45 Brazilian sugar-cane spirits analyzed, 7 showed excess of higher alcohol, 2 showed excess of aldehydes and 3 showed excess of organic acids, therefore $24,4 \%$ of Brazilian sugar-cane spirits analyzed were out of the standard quality established by MAPA (1997).

INDEX TERMS: Secondary compounds, Brazilian sugar-cane spirit, cachaça.

\footnotetext{
1. Engenheiro Agrônomo, D.S, pesquisadora FAPEMIG - Departamento de Química/UNIVERSIDADE FEDERAL DE LAVRAS-UFLA, Caixa Postal 37, 37200-000, Lavras, MG.

2. Professora do Departamento de Química da UFLA.

3. Engenheiro Agrônomo, D.S., pesquisador CNPq/DQI/UFLA.

4. Departamento de Ciências Exatas da UFLA.

5. Bolsistas de Iniciação Científica do CNPq/DQI/UFLA.
} 


\section{INTRODUÇÃO}

Segundo a Associação Brasileira de Bebidas (ABRABE), estima-se que a produção nacional de cachaça encontra-se em torno de 1,5 bilhão de litros por ano. Isso corresponde a um consumo de 11 litros/habitante/ano. Esse destilado vem movimentando nesses últimos anos cerca de US\$ 6,0 bilhões anuais, importância essa que tende a aumentar em virtude da recente denominação de origem que classificou a cachaça como sendo um produto típico do Brasil pelo Decreto $n^{\circ} 4062$ de 21/12/2001 (BRASIL, 2001; RIBAS, 1996).

O Estado de Minas Gerais destaca-se como um dos grandes centros produtores de cachaça, principalmente de cachaça artesanal, cujos procedimentos para produção encontram-se regulamentados pelo Decreto $\mathrm{n}^{\mathrm{o}}$ 42.644, de 5 de junho de 2002 (OLIVEIRA e MAGALHÃES, 2002). O agronegócio da cachaça vem desempenhando um importante papel na estruturação de milhares de propriedades rurais do interior de Minas Gerais. Aproximadamente 8.466 alambiques mineiros apontados pelo IBGE geram cerca de 240.000 empregos diretos e indiretos. Minas Gerais produz cerca de 44,7 milhões de litros de aguardente; porém, acredita-se que esse dado esteja subestimado em virtude da grande clandestinidade do setor. Segundo a Associação Mineira dos Produtores de Aguardente de Qualidade (AMPAQ), estima-se que Minas produza um total de $160 \mathrm{mi}$ lhões de litros (SEBRAE-MG, 2001).

A cachaça é um produto de importância econômica crescente, de grande aceitação no mercado nacional e internacional, justificando, assim, a necessidade de se conhecer a composição físicoquímica, tanto inorgânica (metais e outros) como orgânica (componentes secundários) desse tipo de bebida. Os componentes da cachaça classificados como secundários constituem um grupo de produtos minoritários oriundos do processo de fermentação do mosto, tais como álcoois e outros hidrocarbonetos carbonilados superiores, isto é, com três ou mais átomos de carbono. Esses compostos, especialmente os ésteres e aldeídos, são responsáveis pelo aroma e sabor dos destilados em geral (VALSECHI, 1960; AQUARONE et al., 1983).

O processo de fermentação ocorre graças à ação de enzimas provenientes de certos microrganismos, tais como as leveduras, que transformam os açúcares presentes no mosto em etanol, gás carbônico, glicerina e outros produtos formados em quantidades menos relevantes, tais como ácidos carboxílicos, metanol, ésteres, aldeídos e álcoois superiores. As quantidades verificadas desses compostos variam muito de cachaça para cachaça, ultrapassando, em alguns casos, aos níveis permitidos pelo Ministério da Agricultura, Pecuária e Abastecimento (MAPA) (BRASIL, 1997), daí a necessidade de o produtor estar sempre atento ao processo de fabricação da aguardente, por meio da realização periódica de análises físico-químicas, principalmente no início da safra de cana e do processo de destilação (AQUARONE et al., 1983; PIGGOTT et al. 1989).

Pela legislação brasileira atual (BRASIL, 1997), as quantidades de compostos secundários totais, excluindo-se o etanol em cachaça, devem estar dentro dos limites de $200 \mathrm{mg}$ a $650 \mathrm{mg} / 100 \mathrm{~mL}$ de álcool anidro, sendo os limites máximos admitidos para cada composto secundário de $150 \mathrm{mg}$ de acidez volátil em ác. acético; $200 \mathrm{mg}$ de ésteres em acetato de etila, $30 \mathrm{mg}$ de aldeído expresso em acetaldeído, $5 \mathrm{mg}$ de furfural, 10 $\mathrm{mg}$ de metanol e $300 \mathrm{mg}$ de álcoois superiores $/ 100 \mathrm{~mL}$ de álcool anidro.

Os álcoois com mais de dois átomos de carbono formados durante o processo fermentativo são conhecidos como óleo fusel ou óleo de cana. Esses são provenientes, em grande parte, de reações de degradação de aminoácidos que ocorrem durante o processo de fermentação. Aplicando-se esse tipo de reação a certos aminoácidos, pode-se explicar a formação dos principais álcoois superiores, como o álcool d-amílico a partir da d-leucina, o álcool isoamílico a partir da l-leucina e o álcool isobutílico a partir da valina, os quais apresentam odores característicos freqüentemente encontrados em bebidas (YOKOYA, 1995).

Os aldeídos, principalmente o acetaldeído, são co-produtos normais da fermentação alcóolica. A formação desse tipo de composto é resultado da ação de leveduras durante estágios preliminares do processo de fermentação, tendendo a desaparecer nas etapas finais, desde que o mosto sofra aeração. Os demais aldeídos são obtidos, provavelmente, a partir da oxidação de álcoois superiores provenientes da degradação de aminoácidos gerados pela hidrólise de proteínas. O furfural, um aldeído de presença rara em algumas cachaças, é resultante da decomposição química de carboidratos. É formado, principalmente, pela pirogenação da matéria orgânica depositada no fundo dos alambiques. A sua for- 
mação é evitada pela destilação do vinho limpo, livre de substâncias orgânicas em suspensão. Nas cachaças envelhecidas, o furfural pode ser oriundo da ação de ácidos sobre as pentoses e seus polímeros (hemiceluloses). Esse composto pode estar presente no caldo de cana, quando a colheita da cana-deaçúcar for precedida da queima do palhiço (NOVAES, 1974; POTTER, 1980; PIGGOTT et al., 1989; YOKOYA, 1995).

O acetato de etila, principal éster encontrado na cachaça, é obtido pela reação entre pequenas quantidades de etanol e ácido acético, provenientes do processo de fermentação (ROSE e HARRISON, 1970; PIGOTT, 1989). Esse é responsável, quando presente em pequenas porções, pela incorporação de um aroma agradável de frutas na cachaça. Por outro lado, em grandes quantidades, confere à cachaça um sabor enjoativo e indesejado (WINDHOLZ, 1976).

Na presença de oxigênio e utilizando-se o levedo Saccharomyces cerevisiae, o açúcar pode ser convertido em ácido acético. Na ausência do mesmo, essa levedura produz apenas pequenas quantidades de ácido acético. Quantidades elevadas desse ácido carboxílico são, freqüentemente, associadas a práticas de estocagem da cana e contaminações do mosto com bactérias acéticas, decorrente de um tempo excessivo de descanso entre o processo de fermentação e a destilação (FARIA, 1989; CARDOSO, 2001)

Devido a esses fatores, com o presente trabalho objetivou-se principalmente verificar a presença de compostos secundários de diferentes aguardentes analisadas no Laboratório de Análises Físico-Químicas de Aguardente (LAFQA) /DQI - Universidade Federal de Lavras, Lavras, MG.

\section{MATERIAL E MÉTODOS}

\section{Obtenção das aguardentes}

Quarenta e cinco diferentes cachaças comerciais (cachaça de coração) provenientes de diversas localidades do Estado de Minas Gerais foram coletadas e levadas ao Laboratório de Análises Físico-Química de Aguardente (LAFQA)/DQI - Universidade Federal de Lavras (Lavras, MG), para a realização de análises físico-químicas, no período de agosto de 2000 a julho de 2001. Foi coletado um volume de 1 a 1,5 litro do destilado em garrafas de vidro limpas e desinfetadas que, após a coleta da cachaça de cabeça foram fechadas com rolhas novas e remetidas imediatamente para análise laboratorial.

\section{Delineamento experimental}

O delineamento experimental utilizado foi inteiramente casualizado com duas repetições e 45 tratamentos.

\section{Análises Físico-Químicas}

As análises físico-químicas das aguardentes estudadas foram realizadas de acordo com os procedimentos laboratoriais determinados pelo Decreto Federal $\mathrm{n}^{\circ} 2314$, de 4 de setembro de 1997 , que regulamenta a Lei $\mathrm{n}^{\circ} 8918$, de 14 de julho de 1994, sobre os padrões físico-químicos admitidos para a bebida (BRASIL, 1997), os quais são apresentados sinteticamente:

\section{Álcoois Superiores}

A quantidade total de álcoois superiores foi determinada por meio de medidas espectrofotométricas efetuadas na região visível do espectro $(540 \mathrm{~nm})$. Essa quantificação foi realizada comparando-se os valores de absorbância referentes às amostras com uma curva de calibração construída previamente, utilizando-se uma mistura de álcoois superiores solubilizada em solução água/etanol 1:1.

\section{Acidez Volátil}

A acidez volátil das amostras foi determinada por meio da extração dos ácidos voláteis, utilizando-se técnicas de arraste por vapor de água. O extrato obtido foi titulado por meio de métodos de titulação ordinários. Os resultados das análises foram expressos em gramas de ácido acético por $100 \mathrm{~mL}$ de amostra ou gramas desse mesmo composto por $100 \mathrm{~mL}$ de álcool anidro.

\section{Determinação de aldeídos}

Os aldeídos das amostras de cachaça foram analisados por métodos iodométricos, titulando-se o $\mathrm{SO}_{2}$ produzido durante a sequiência de reações utilizadas neste tipo de análise. A quantidade de aldeídos presentes nas amostra foi expressa em gramas de aldeído acético por $100 \mathrm{~mL}$ de amostra ou $100 \mathrm{~mL}$ de álcool anidro.

\section{Determinação de ésteres}

Os ésteres presentes nas cachaças foram determinados por titulação dos ácidos carboxílicos obtidos por transesterificação dos ésteres presentes nas amostras de aguardentes. A quantidade total desses ésteres 
foi expressa em gramas de acetato de etila por $100 \mathrm{~mL}$ de amostra.

\section{RESULTADOS E DISCUSSÃO}

Na Tabela 1 encontra-se o resultado da análise de variância para as diferentes análises fisico-químicas realizadas. Observa-se que para todas as análises houve diferenças altamente significativas entre tratamentos; o furfural foi o único composto secundário não analisado nesta pesquisa, porém não se consiste em um problema freqüente nas cachaças.

O fato de as análises apresentarem diferenças altamente significativas entre as amostras já era esperado, visto que o universo amostral, representado pelas 45 cachaças analisadas, representou a grande diferença quanto à qualidade físico-química que pode existir entre diferentes cachaças, que se distinguem quanto ao grau alcoólico que, no presente trabalho, variou de 34 a $50^{\circ}$ G.L., e as cachaças 11,25 e 30 encontravam-se fora do limite obrigatório estabelecido pelo MAPA (BRASIL, 1997) para uma bebida ser considerada uma cachaça (Figura 1).

Pelas análises estatísticas, também demonstrou-se que dentre os compostos secundários analisados, o éster foi o que apresentou maior coeficiente de variação (26\%), significando que houve diferenças entre repetições, apesar dos cuidados tomados durante os procedimentos de análise, o que indica um aumento no erro experimental. Um procedimento recomendado nesses casos seria aumentar o nú- mero de repetições para maior confiabilidade dos resultados, principalmente quando se verificam valores de éster próximos ao limite permitido em análises físico-químicas de cachaças. Esse não foi o caso dos resultados verificados neste trabalho para as análises de éster nas cachaças (tabela 1), cujos valores verificados ficaram entre 13,79 e $161 \mathrm{mg} / 100$ $\mathrm{mL}$ de álcool anidro, portanto, abaixo do limite máximo permitido pelo Decreto do MAPA (1997). Isso demonstra que a formação de éster no processo fermentativo das amostras analisadas não se encontra fora da faixa estabelecida oficialmente.

Segundo Windholz (1976), a formação do acetato de etila, muitas vezes, é favorecido pelo abaixamento da temperatura do mosto durante o processo de fermentação. Procedimentos como adição de água aquecida ao se diminuir o brix do caldo, ou mesmo aquecimento do caldo de cana, muitas vezes antes de ser transferido as dornas de fermentação, contribuem para minimizar uma formação de acetato de etila acima dos limites oficialmente admitidos.

Das quarenta e cinco aguardentes, sete $(16,24$, $27,33,3435$ e 42) apresentaram álcoois superiores (Figura 2) fora do limite oficial estabelecido, o que representou 15,6\% das aguardentes analisadas. De acordo com Yokoya (1995), a formação de álcoois superiores é maior quando o fermento apresenta atividade fraca, ocasionando demora no processo fermentativo. De acordo com Silva et al. (1996), a ação microbiana durante a fermentação anaeróbia resulta também em aumento de álcoois superiores.

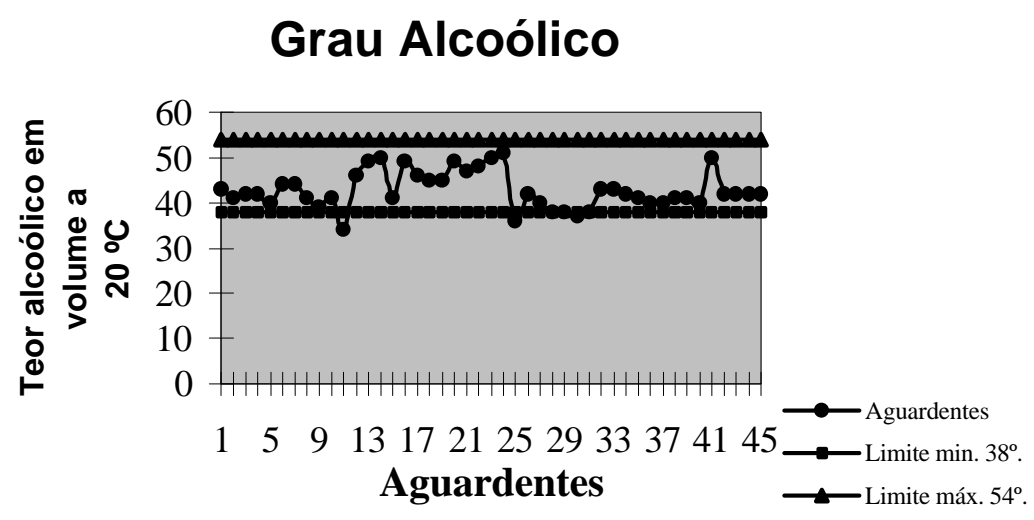

FIGURA 1 - Valores de grau alcoólico das diferentes amostras analisadas e limite mínimo e máximo para um destilado ser considerado uma cachaça. 
Outro fator pouco considerado pelos produtores de cachaça é a definição do ponto de corte das frações do processo de destilação da cachaça denominadas de cabeça, coração e cauda. De acordo com Chaves (1998), em geral, denomina-se de cachaça de cabeça os $10 \%$ iniciais do processo de destilação e cachaça cauda os $10 \%$ finais. Maia (1994) verificou que os álcoois superiores devem incorporar-se principalmente ao destilado de cauda, que, em média, apresenta um grau alcoólico abaixo de $10^{\circ} \mathrm{G}$.L. Alguns produtores consideram os $10 \%$ finais como sendo a fração cauda; porém, esse ponto de corte varia muito de produtor para produtor, havendo casos em que o ponto de corte é muito baixo (menor que $2 \%$ ), o que pode ocasionar um aumento de álcoois superiores na cachaça de coração.

A rota biossintética desse tipo de composto pode sofrer variação, dependendo da linhagem do levedo. A formação de álcoois superiores também pode ser influenciada por variáveis, tais como: concentração de aminoácidos e pH do mosto, temperatura de fermentação, nível de inoculação, intervalo de tempo entre a fermentação e a destilação e tempo prolongado de armazenamento da cana, o que ocasiona a degradação de aminoácidos como a d-leucina e a valina (CROWELL et al., 1961; AYRAPAA, 1970; ENGAN, 1970).

Duas das cachaças analisadas (17 e 32) apresentaram excesso de aldeídos (Figura 2). Esses são comuns no processo inicial da fermentação, tendendo a desaparecer no final. A causa do excesso de aldeídos nas cachaças pode ser uma indicação de oxidação espontânea ou devido à atividade de bactérias contaminantes (YOKOYA, 1995; SILVA et al., 1996).

A acidez volátil é outro composto secundário que depende do processo fermentativo, e o controle dos fatores cepa da levedura utilizada, pureza da fermentação, tempo e temperatura da fermentação, manejo do mosto e principalmente higienização são essenciais para minimizar a ocorrência do mesmo (CARDOSO, 2001). Na presente pesquisa, três amostras (16, 20 e 41) apresentaram acidez volátil acima do limite oficial máximo (Figura 2).

A soma do total de compostos secundários revelou que nenhuma das cachaças encontravam-se fora dos limite mínimo (200 mg/ $100 \mathrm{~mL}$ de álcool anidro) e máximo $(650 \mathrm{mg} / 100 \mathrm{~mL}$ de álcool anidro) estabelecidos pelo MAPA (1997) para uma cachaça ser considerada dentro dos padrões de qualidade. Porém, observou-se que, pela avaliação individual de cada análise físico-química, quatorze cachaças encontravam-se fora dos limites estabelecidos oficialmente, representando $24,4 \%$ das cachaças analisadas.

$\mathrm{O}$ universo amostral da presente pesquisa foi mais complexo do que o esperado, com diferentes marcas de cachaça comercializadas e produzidas em diferentes alambiques, onde, muitas vezes, o empirismo determina a melhor prática, o tempo de realização e material utilizado pelo produtor, o que, muitas vezes, dificultava o diagnóstico do problema, que foi estudado caso a caso. Portanto, no ato da divulgação dos resultados, todos os produtores cujas cachaças apresentavam-se fora dos padrões oficiais foram orientados quanto aos possíveis fatores que estariam contribuindo para esse fato e como solucioná-los.

TABELA 1 - Média, desvio padrão, coeficiente de variação e significância da análise de variância dos compostos secundários encontrados nas amostras de cachaça.

\begin{tabular}{lcccc}
\hline Composto Secundário & Álcool superior & Aldeído & Éster & Acidez volátil \\
\hline Média $^{(1)}$ & 222,35 & 13,59 & 5,15 & 77,79 \\
Desvio padrão & 67,38 & 8,20 & 3,32 & 49,49 \\
C.V. & 2,27 & 2,86 & 26,30 & 2,25 \\
Significância & $* *$ & $* *$ & $* *$ & $* *$ \\
\hline
\end{tabular}

\footnotetext{
${ }^{(1)}$ dados em mg/100 mL de álcool anidro.
}

C.V.= coeficiente de variação.

**= diferença entre as amostras analisadas altamente significativa. 


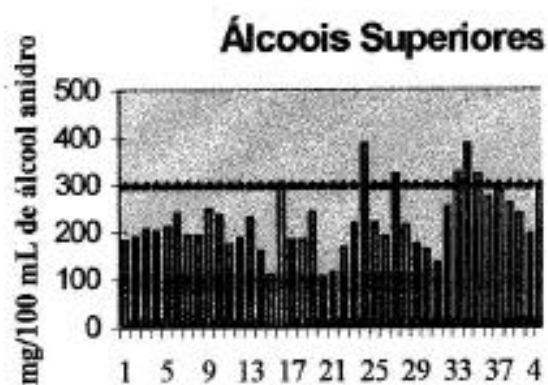

Aguardentes

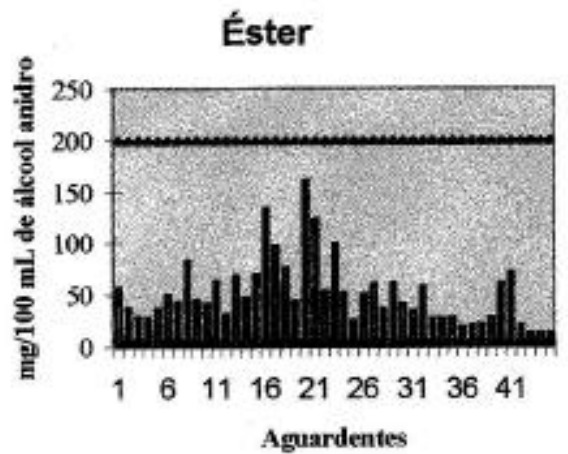

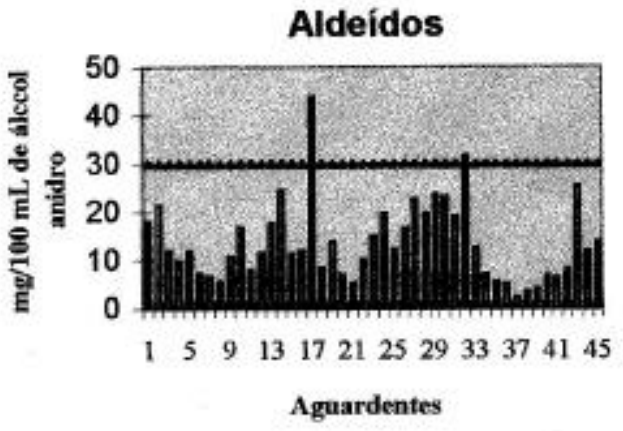

Acidez Volátil

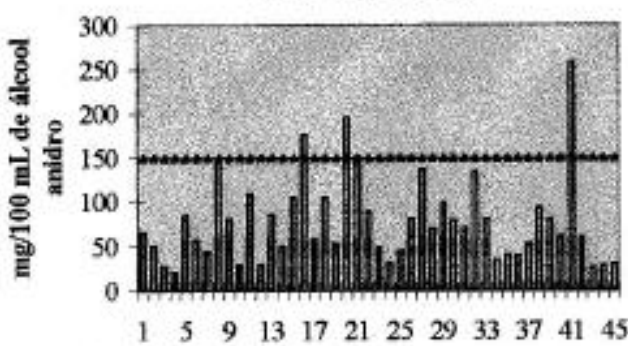

Aguardentes

Total dos Compostos Secundários

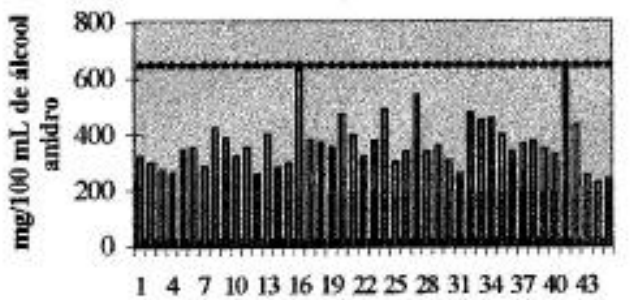

Agrandentes $\quad \rightarrow$ Limite máx. permitido

FIGURA 2 - Concentrações de álcoois superiores, aldeídos, éster, acidez volátil e total de compostos secundários nas diferentes aguardentes analisadas e seus limites máximos permitidos pelo Decreto federal 2314, de 4 de setembro de 1997, do MAPA.

Segundo Oliveira e Oliveira (2000), a clandestinidade na produção de cachaça em todo o território nacional é elevada. Estima-se que $90 \%$ das aguardentes produzidas no Brasil não tenham registro no Ministério da Agricultura, o que dificulta a sua fiscalização. Observa-se nesta pesquisa que mesmo em um grupo de produtores que são conscientes da necessidade de se fa- zer análise físico-químicas de suas cachaças, ainda encontra-se uma alta porcentagem de cachaças fora do padrão de qualidade determinado pelo MAPA (1997), o que ressalta a necessidade de uma melhor divulgação técnica, por meio de cursos de capacitação profissional ou mesmo por informes em meios de comunicação de massa, que venham a orientar produtores e iniciantes 
sobre os procedimentos básicos para se obter uma cachaça de qualidade.

\section{CONCLUSÕES}

No presente estudo, verificou-se que $24,4 \%$ das cachaças analisadas apresentaram-se fora dos limites estabelecidos pela análise oficial para, no mínimo, um dos compostos secundários analisados, tendo sido verificados, em algumas cachaças, álcool superior, aldeídos e acidez volátil acima dos limites estabelecidos.

\section{AGRADECIMENTOS}

À Fapemig e ao CNPq, pelo auxílio ao projeto de pesquisa e pelo fornecimento de bolsas de iniciação científica, recém-doutor e produtividade.

\section{REFERÊNCIAS BIBLIOGRÁFICAS}

AQUARONE, E.; LIMA, U. de A.; BORZANI, W. Alimentos e bebidas produzidos por fermentação: biotecnologia. São Paulo: Edgard Blücher, 1983. v. 5, 43 p.

AYRAPAA, T. Effect of temperature on the formations of higher alcohols by culture yeasts. Brauwissenschaft, Nurnberg, v. 23, p. 48-55, 1970.

BRASIL. Ministério da Agricultura Pecuária e do Abastecimento. Decreto $n^{\circ}$ 2314, de 4 de setembro de 1997 que regulamenta a Lei de 8918 de 14 de julho de 1994. 1997. Disponível em: <htpp://www.agricultura.gov.br/das/ ddiv/pdf/decreto_2314_1997_Lei_8918_1994.pdf>. Acesso em: 29 mar. 2003.

BRASIL. Ministério da Agricultura Pecuária e do Abastecimento. Decreto $\mathbf{n}^{0}$ 4062, de 21 de dezembro de 2001. 2001. Disponível em: <htpp://www.agricultura.gov.br/das/ddiv/pdf/decreto_4 062_2001.pdf)>. Acesso em: 29 mar. 2003.

CARDOSO, M. das G. Análises físico-químicas de aguardente. In: . Produção de aguardente de cana-deaçúcar. Lavras: UFLA/FAEPE, 2001. p. 152-173.

CHAVES, J. B. P. Cachaça: produção artesanal de qualidade. Viçosa: CPT, 1998. 78 p. Manual Técnico.

CROWELL, E. A. Techniques for studying the mecanism of higher alcohol formation by yeasts. American Journal Ecology and Viticulture, Washington, v. 12, p. 111-6, 1961.
ENGAN, S. The influence of some aminoacids on the formation of highter aliphatic alcohol and esters. Journal Institute of Brewing, London, v. 76, p. 254-256, 1970.

FARIA, J. B. A influência do cobre na qualidade das aguardentes da cana (Sacharum officinarum L.). 1989. Tese (Doutorado) - Faculdade de Ciências Farmacêuticas, Universidade de São Paulo, São Paulo, 1989.

MAIA, A. B. Componentes Secundários da Aguardente. STAB, Piracicaba, v. 12, n. 6, p. 29-34, jul./ago. 1994.

MINISTÉRIO DA AGRICULTURA, PECUÁRIA E DO ABASTECIMENTO. Dos destilados alcoólicos e das bebidas alcoólicas destiladas. Decreto Federal $\mathbf{n}^{0}$ 2314 de 04/08/1997. Brasília, 1997. cap. 4.

NOVAES, F. V. Primeiro curso de extensão em aguardente de cana. Piracicaba: ESALQ, 1974.

OLIVEIRA, E. R.; OLIVEIRA, E. C. M. Produção artesanal de cachaça em Minas Gerais: o mito da qualidade da cachaça de Salinas. In: CONGRESSO BRASILEIRO DE CIÊNCIAS E TECNOLOGIA DE ALIMENTOS, 17., 2000, Fortaleza. Resumos... Fortaleza: [s.n.], 2000. p. 3166.

OLIVEIRA, S. G. de; MAGALHÃES, M. A. Procedimentos para produção da cachaça artesanal de Minas regulamentados pelo decreto $n^{\circ} 42.644$ de 05/06/2002. Informe Agropecuário, Belo Horizonte, v. 23, n. 217 , p. 78-83, 2002.

PIGOTT, J. R. (Ed.). Distilled beverage flavour. Weinheim: VCA, 1989.

PIGGOTT, J. R.; SHARP, R.; DUCAN, R. E. B. The science and technology of whiskies. New York: Longman, 1989. $410 \mathrm{p}$.

POTTER, N. N. Food science. Westport: AVI, 1980.

RIBAS, S. Empresas mineiras lançam cachaças. Gazeta Mercantil. Belo Horizonte, 23 maio 1996.

ROSE, A. H.; HARRISON, J. S. (Eds.). The yeasts. London: Academic, 1970.

SEBRAE-MG. Diagnóstico da cachaça de Minas Gerais. Belo Horizonte, 2001. 259 p. 
SILVA, M. L.; MALCATA, F. X.; REVEL, G. de. Volatile contents of grape marcs in Portugal. Journal of food composition and analysis, Orlando, v. 9, p. 72$80,1996$.

VALSECHI, O. Aguardente de cana-de-açúcar. Piracicaba: Livroceres, 1960.
YOKOYA, F. Fabricação de aguardente de cana. Campinas: Fundação Tropical de Pesquisas e Tecnologia "André Tosello", 1995. 87 p. (Série Fermentações Industriais).

WINDHOLZ, M. (Ed.). The merck index. Rahway: Merck, 1976 